\title{
Food Allergy, a Newly Emerging Food Epidemic: Is the Current Regulation Adequate?
}

\author{
N. Alice Lee* \\ School of Chemical Engineering, Food Science and Technology, \\ University of New South Wales, Sydney NSW 2052, Australia \\ (Received October 11, 2012/Revised November 9, 2012/Accepted November 24, 2012)
}

\begin{abstract}
Food allergy refers to an immunologically mediated adverse reaction to food, mainly to proteinaceous constituents. Health implications vary between those individuals who experience mild physical discomforts to those with fast-acting, life-threatening anaphylactic reactions. The prevalence of food allergy is higher in children than in adults, estimated around $4-8 \%$ and $1-2 \%$ respectively in developed countries. Food allergy has no effective cure at the present time and total avoidance of causative foods is the most reliable prophylactic method currently recommended by the medical community. To help food allergic patients to make informed choices of their foods, mandatory labeling of selected food allergens has been introduced in several countries. All food allergen labelling provisions specify a set of allergens common to the regulated countries. Policy divergence, however, exists between countries by inclusion of additional allergens unique to specific countries and enforcement of specific labelling requirements. Such variations in food allergen labelling regulations make it difficult to manage allergen labeling in imported pre-packaged food products. This paper addresses two current issues in food allergen regulation: 1) an urgent need to determine true prevalence of food allergy in the Asia-Pacific region. This will enable refinement to the food allergen regulation to be more country-specific rather than simply adopting CODEX recommendations. 2) There is an urgent need for harmonization of food allergen regulation in order to prevent food allergen regulation becoming a trade barrier.
\end{abstract}

Key words: food allergy, food safety, public health, mandatory declaration, harmonization, trade barrier

\section{Introduction}

Most of us enjoy food every day without much fuss. For a small but increasing population of people, however, consumption of certain foods can be an unhappy event as they cause undesirable physiological reactions in the body. Such adverse reactions to food are called food sensitivity. Adverse reactions to food can be divided into two general categories, depending on the involvement of an immune system. Those reactions that are not mediated by the immune response are generally called food intolerance. Examples of food intolerance include lactose intolerance (alactasia), intolerance to some food additives such as sulfite, benzoates and azo- dyes, some naturally occurring biogenic amines, and monosodium glutamate (MSG) that is sometimes called the Chinese restaurant syndrome ${ }^{1)}$.

Food allergy refers to an adverse reaction that involves an

\footnotetext{
*Correspondence to: Alice Lee, University of New South Wales, School of Chemistry Engineering, Food Science and Technology Anzac Parade, 2052 NSW Australia

Tel: 61-2-97590439, E-mail: alice.lee@unsw.edu.au
}

immune reaction to an ingested food, mainly to proteins. Unlike, food intolerance, where the reaction is generally slow and shows symptoms within days of food consumption, food allergy can trigger immediate reaction occurring within minutes. The symptoms of food allergy vary drastically between sensitive individuals, exhibiting mild conditions such as respiratory (asthma, rhinitis), cutaneous (eczema, urticaria) or gastrointestinal (vomiting, diarrhea) symptoms) to life threatening anaphylatic shock ${ }^{2}$.

It is well-established that genetic factors strongly influence the development of food allergy. Environmental factors such as changing environments, increasing air pollution, changing diets, and increased exposure to food additives and preservatives, have been hypothesized to play an important role in the food allergy development ${ }^{3,4}$. In genetically predisposed individuals, the interaction between food proteins and their immune system can be simplified into two phases (Fig. 1); the first phase is called sensitization and the second, elicitation ${ }^{5)}$. Sensitization is a phase during which the absorbed food proteins induce the production of immunoglobulin $\mathrm{E}$ (IgE). The IgE molecules, which circulate in the body, attach to specialized cells called basophils and mast cells. In a sen- 


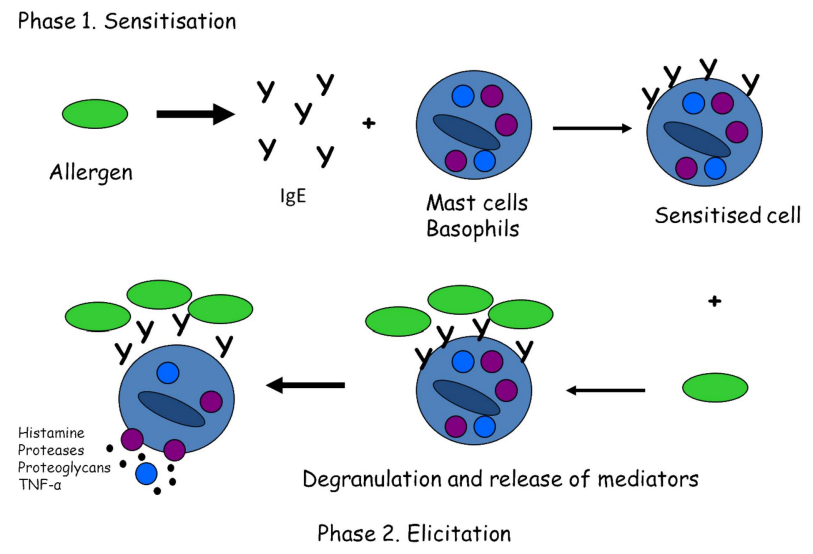

Fig. 1. How an allergen induces an allergic reaction.

sitized individual (and during the elicitation phase), the same food proteins when re-introduced into the body bind to the $\mathrm{IgE}$ affixed to the mast cells or basophils. This results in cross-linking of IgEs and allergenic molecules, and triggering the release of inammatory mediators such as histamine. The mediators interact with specific receptors present in various parts of the body, leading to the symptoms of allergic reactions.

\section{Food allergens}

Major food allergens are divided into plant food origin and animal food origin. The major plant food allergens include peanuts, tree nuts, soybeans and other legumes, and cereals. The animal food allergens include cow's milk, eggs, fish and shellfish and crustacean. An analysis of major food allergens according to protein families were narrowed down to 7 major protein families that accounted for $>60 \%$ of food allergens ${ }^{6,7)}$.
For plant food allergens, these are prolamin, prolin, cupin and Bet v 1 families, and for animal food allergens, tropomyosin, parvalbumin and casein families are the dominant protein families. These observations suggest that food allergens share common protein structures that are highly conserved among the allergens and demonstrate similar properties such as high tolerance to acid and heat and high resistance to proteolytic hydrolysis. In general, more than one allergenic protein is present in an allergenic food and their relative allergenicity varies significantly. Some of the major plant and animal allergens are described below and the list of allergens identified from the major allergenic foods is given in Table 1.

\section{Egg Allergens}

Egg allergy is one of the most prevalent food allergies in childhood, accounting for $1.6-3.2 \%$ of children ${ }^{8)}$. Only $0.2 \%$ of adult population experience allergic reaction to egg allergens, showing the outgrowing rate to be relatively high ${ }^{9}$. Egg allergy in infants appears to have occurred before their first exposure to egg protein in infant weaning foods, suggesting they may have been sensitized via other routines such as via in-uterus exposure before birth ${ }^{10)}$. Both egg white protein and egg yolk protein are potentially allergic, but only egg white proteins have shown clinical symptoms. The identified egg white allergens include ovoalbumin, ovmucoid, ovotransferrin, ovomucin and lysozyme. The egg yolk allergens are apovitellenins I and IV and phosvitin ${ }^{11)}$.

\section{Cow's Milk Allergens}

Cow's milk allergy (hereafter referred as milk allergy) is also one of the most prevalent food allergies in childhood,

Table 1. Major allergenic foods and their allergenic proteins

\begin{tabular}{|c|c|c|}
\hline Allergenic Foods & Identified Allergens & Allergen Designation \\
\hline Peanuts & Vicillin, conglutin, glycinin & $\begin{array}{l}\text { 7S seed storage protein (Ara h1), 2S see storage protein (Ara 2, Ara 6, } \\
\text { Ara h7), 11S seed storage protein (Ara h3, Ara h4) }\end{array}$ \\
\hline Tree nuts & Vicillin, conglutin, glycinin & $\begin{array}{l}\text { 7S seed storage protein (Jug r2 (Brazil nut), major protein in almond, Ana } \\
\text { o1 (cashew), Cor a11 (hazelnut), 2S albumin (almond, Ber e1 (Brazil } \\
\text { nut), Jur r1 (walnut), Ana o3 (cashew nut)), 11S see storage protein (Ber } \\
\text { e2 (Brazil nut), Ana o1 (cashew nut) Cor a9 (hazelnut)), other proteins } \\
\text { (Cor a8 (hazel nut), Jug r3 (walnut), Cor a1.0401 (hazel nut) }\end{array}$ \\
\hline Crustacean & Tropomyosin & Pen i1 \\
\hline Fish & Parvalbumin & $\begin{array}{l}\text { Gad c1 (cod), Sal s1 (Atlatic salmon), Tra j1 (horse mackerel), Sco } \mathrm{j} 1 \\
\text { mackerel Thu o1 from bigeye tuna, Ang } \mathrm{j} 1 \text { from Japanses eel, The c1 } \\
\text { from pollack and cyp } 1 \text { from carp }\end{array}$ \\
\hline Milk & $\begin{array}{c}\text { Caseins }(\alpha, \beta, \kappa) \\
\beta \text {-lactoglobulin, } \alpha \text {-lactoalbumin }\end{array}$ & Bos d8, Bos d5, Bos d4 \\
\hline Eggs & Ovomucoid, ovalbumin, ovotransferrin & Gal d1, Gal g2 \\
\hline Soybeans & Glycinin, profilin, trypsin inhibitor & Gly m4, Gly m Bd 30k \\
\hline Wheat/Cereals & Gluten & Gliadin, Glutenins \\
\hline Sesame & Seed storage proteins & $2 \mathrm{~S}$ albumin $(\operatorname{Ses} \mathrm{j} 1, \mathrm{Ses} \mathrm{j} 2)$ \\
\hline Mustard & Seed storage proteins & $2 \mathrm{~S}$ albumin (Bra j1 and $\mathrm{Sin} \mathrm{a} 1)$ \\
\hline
\end{tabular}


accounting for $1.6-2.5 \%$ of children ${ }^{12,13)}$. Milk allergy usually develops in the first year of life and typically occurs after either first or second exposure to milk allergens in infant formula ${ }^{12)}$. The prevalence in adult is significantly lower than that in children, indicating high outgrowing rate. The relative allergenicity of milk proteins is yet to be confirmed, however, it is commonly agreed that casein, $\alpha$-lactoalbumin, and $\beta$-lactoglobulin are the major allergens in milk.

\section{Peanut Allergens}

Peanut allergy is becoming more significant as its prevalence is continuing to rise, but the reasons for such rise are not clear. The prevalence of peanut allergy is somewhat similar in both children and adults $(0.4-0.6 \%$ and $0.3-0.7 \%$ respectively $)^{14,15)}$. Grundy et al. ${ }^{16)}$, however, determined higher prevalence rate of $1.2-1.5 \%$ in children. From the clinical point of view, peanut allergy is more serious than other food allergies in that the reactions could lead to life threatening events and that the outgrowing rate of this allergy in adulthood is low $(<20 \%)^{17)}$. The vast majority of reported anaphylaxis in the UK and the US is caused by peanuts and tree nuts ${ }^{18)}$. To date, eleven allergenic proteins have been identified and named according to their chronological discovery ${ }^{19-23)}$. Peanut allergens belong to seed-storage proteins in vicillin, conglutin, and glycinin superfamilies. Of eleven allergens, Ara h1, Ara h2/h6 and Ara h3 are the major allergens as assessed by serum $\operatorname{IgE}$ interaction, and with greater abundance in peanut kernel.

\section{Fish allergens}

Fish allergy is generally high in countries where fish is commonly consumed in diet, and more prevalent in adults than in children, which seems to link to consumption patterns primarily. The prevalence of fish allergy between countries, different cohorts and different fish species varies greatly. Fish allergy is one of the highly prevalent food allergy in Korean, possibly due to abundance of fish and aqua-cultural foods ${ }^{24)}$. The most studied major fish allergen is Gad c1, a highly water soluble parvalbumin from Baltic $\operatorname{cod}^{25,26)}$. Other parvalbumins from various fish species have been discovered as major fish allergens and these are Sal s1 from Atlantic salmon, Tra j1 from horse mackerel, Sco $\mathrm{j} 1$ from mackerel Thu o1 from bigeye tuna, Ang j1 from Japanses eel, c1 from pollack and cyp 1 from carp ${ }^{27)}$. Parvalbumin is extremely stable against heat treatment, exposure to reducing agents, and resistant to enzymatic degradation ${ }^{28)}$. Cross-reactivity between different fish species is common due to the highly conserved structure of parvalbumins from different species. In addition, crossreaction between fish and frog parvalbumin has also been reported ${ }^{29)}$.

\section{Prevalence of Food Allergy}

Prevalence of IgE-mediated food allergy can vary significantly depending on the method used. Many of the earlier studies relied solely on questionnaire surveys, and only a few studies employed medical diagnosis (e.g., a positive skin prick test result and relevant clinical history). The prevalence derived from self-reported food allergy is generally higher than that of medically diagnosed food allergy. Thus this fails to reflect the true prevalence of food allergy. For example, the self-reported food allergy in Asia reported a rate of 4$10.9 \%$, whereas the medically diagnosed food allergy indicated a lower rate of $<6 \%{ }^{30)}$. IgE-mediated food allergy is more prevalent in childhood than in adulthood in developed countries, affecting $4-8 \%$ of children and $1-2 \%$ in adult $t^{31)}$. Evidence indicated by prevalence studies also showed an increasing trend of food allergy, estimated to have doubled in the last two decades ${ }^{31)}$.

Food allergy can affect humans of all ages, however, different age groups appear to experience different food allergies. Allergic reactions from fruits, vegetables, tree nuts and peanuts are more commonly reported among adults, whereas incidences from egg, peanut, milk, fish and nuts are more common among children ${ }^{32)}$. Furthermore, different geographical regions show different prevalence to different food allergies. This is partly due to different dietary exposure at early ages and the availability of geographically unique and specific foods that may cause allergic reactions.

Compared to western countries, the prevalence of food allergy in Asia is seemingly lower, possibly due to lack of accurate medical diagnosis and hospital records related to food allergy. Analyzing the available patient-reported, questionnaire and phone survey in several Asian countries, however, revealed high prevalence in children; $4.98 \%$ in China, 4.6-8.1\% in Hong Kong, $10.9 \%$ in Korea, $4-5 \%$ in Singapore, $5.5 \%$ in Japan and $6.25 \%$ in Thailand ${ }^{33)}$. The clinical studies based on skin prick tests which indicate potential sensitization, however, revealed contradicting results, with higher prevalence occurring in China $(25.3 \%)$ and lower in Thailand $(0.45 \%)^{30)}$. Further studies based on medical diagnostic approach are needed to confirm the true prevalence of food allergy in Asia.

Comparing prevalence rates also revealed dissimilar food allergic patterns between Western and Asian countries; even among Asian countries. The most common allergens causing anaphylaxis in Japan are milk, eggs, wheat, peanuts and soybeans ${ }^{34)}$. Eggs, cow's milk, fish and shellfish are the most common allergens in Korea ${ }^{23)}$. A birth cohort study in Korea based on 1177 one-year old infants showed the highest prevalent food allergens to be eggs, milk and peanut/nuts ${ }^{35)}$. The major food allergies amongst Chinese living in different geographical regions also differ drastically ${ }^{33)}$. Those from 
the mainland are commonly allergic to eggs, cow's milk, shellfish, peanuts and buckwheat ${ }^{36,37)}$. Those residing in Hong Kong experience allergic reaction to eggs, cow's milk, peanut and beef ${ }^{36)}$. Food allergens that are regionally unique include silkworm pupa (China), buckwheat (Korea, Japan and China), Bird's nest (Singapore), chestnut (Korea), royal jelly (China) and chickpea (India) ${ }^{30,34)}$. The allergenicity of these allergens relative to the major allergens are not well determined and only a very few specific allergenic proteins have been identified. It would be worthwhile to assess their potential risks in the context of public health in future.

\section{Regulation}

Food allergy is a serious health problem for which complete cure is not currently available. Total avoidance of causative foods is the most reliable prophylactic method recommended by the medical community. Such diet therapy, however, accompanies a burden of ensuring absolute safety (by the agricultural and food industries) and nutritional adequacy for sensitive individuals ${ }^{38)}$. Recognising food allergy as an emerging public health issue worldwide, the World Health Organization (WHO) and the Food and Agriculture Organization (FAO) developed a list of allergenic foods which need to be declared on pre-packaged foods ${ }^{39)}$. The intention of food allergen labeling is to inform sensitive individuals of the presence of food allergens, allowing them to make informed decisions and managing their allergy accordingly. A list of major food allergens recommended by CODEX to be declared on food packages includes cereals containing gluten (wheat, rye, barley, oats, spelt, and other hybridized strains), crustacean, egg, fish, peanuts, milk and tree nuts. Since the CODEX recommendation, mandatory food allergen labeling regulation has been implemented by Australia, the US, Canada, European Union, Japan, Korea, China/Hong Kong and other countries. Most of the regulated countries adopted the CODEX recommendation, but either exclude allergens with low prevalence or include specific allergens thought to be important for the particular countries (Fig. 2). In addition, each country developed its own specific requirements for food allergen declaration, for example, the conditions for use of pre-cautionary statements, and a list of exemptions from labelling.

In Australia and New Zealand, allergen labelling provisions were introduced into the Food Standards Code in 2002 by Food Standards of Australia and New Zealand (FSANZ, formerly known as Australia New Zealand Food Agency, ANZFA), adopting the food allergen list recommended by the Codex Alimentarius. Sesame seeds were also included in this $\operatorname{code}^{40)}$. This standard requires mandatory declaration of the 8 major allergens plus sesame seeds, when they are present as an ingredient, an ingredient of a compound ingredient, a

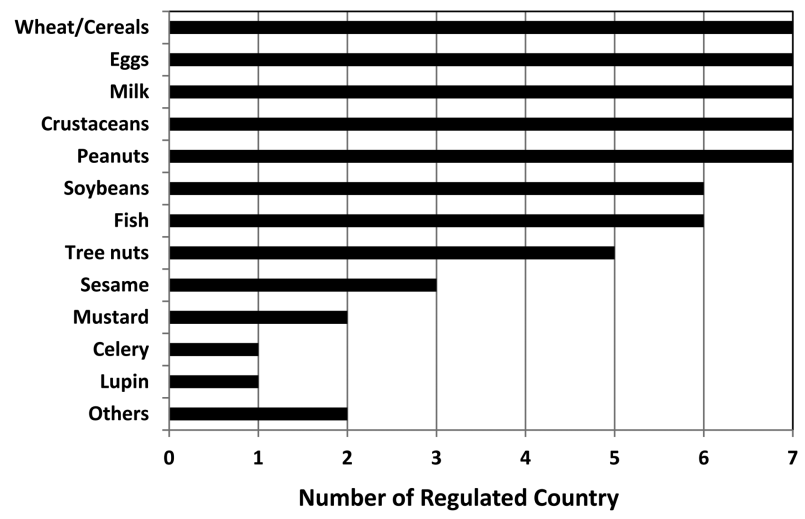

Fig. 2. Comparison of common food allergens regulated by Australia/New Zealand, EU, USA, Canada, Korea, Japan and China/ Hong Kong.

food additive or component or a processing aid or component of a processing aid, but does not include residues occurring unintentionally due to cross-contamination.

The Food Allergen Labeling and Consumer Protection Act of 2004 (FALCPA) was introduced in the United States two years later in $2004^{41)}$. The law applies to all foods, both domestic and imported, whose labeling is regulated by the FDA. It requires that labels must clearly identify the food source names of all ingredients that are or contain any protein derived from the eight most common food allergens, which FALCPA defines as "major food allergens", thus accounting for 90 percent of food allergic reactions. The eight foods identified by the law are milk, eggs, fish (e.g., bass, flounder, cod), crustacean shellfish (e.g., crab, lobster, shrimp), tree nuts (e.g., almonds, walnuts, pecans), peanuts, wheat, and soybeans ${ }^{41)}$.

The Canadian regulatory framework for food allergens also enforces mandatory labelling of the 8 major allergens plus sesame seeds and mustards ${ }^{42)}$. This law, however, differentiates wheat from cereals containing gluten (wheat, oats, rye, barley, triticale a hybridized strain) and specifies specific tree nuts to be declared (almonds, Brazil nuts, cashews, hazelnuts, macadamia nuts, pecans, pine nuts, pistachios and walnuts).

The European Union's (EU) directive (EU Directive 2003/ 89/EC amending 2000/13/EC) introduced mandatory labeling to list 12 potential food allergens on product packages regardless of the quantity in the finished product ${ }^{43)}$. This includes the eight major food allergens recommended by CODEX, plus celery, mustard and sesame seeds.

The Japanese Ministry of Health, Labour and Welfare introduced two food allergen categories for labeling by amending the Food Sanitation Act in 2004 ${ }^{44)}$. The first category is foods for mandatory labelling by Ministerial Ordinance and includes shrimp/prawns, crab, wheat, buckwheat, eggs, milk and peanuts. The second category is a list of foods recommended by notice and includes 18 foods consisting 
foods not listed by other regulations, such as banana, beef, pork, "matsutake" mushrooms, yams, gelatin and oranges.

The Korean Food and Drug Administration introduced mandatory labelling of food allergens at the same time as Japan; however, it differs in the list of foods that is considered major allergens ${ }^{45)}$. This law adopted the eight major foods recommended by Codex, plus pork, peaches and tomatoes. Only wheat and buckwheat are listed for mandatory labeling; mackerel is the only fish listed under fish, and crab and shrimp are the only crustaceans regulated ${ }^{45}$.

On the other hand, China and Hong Kong authorities adopted Codex recommendation wholly without introducing other allergens ${ }^{46)}$. It is unclear whether their decision for adoption is based on country-specific clinical evidence of food allergy prevalence.

Food allergen regulation is further complicated by international trades, increasing demand for product differentiation, rapid development of novel food ingredients and continuous changes in socio-economic factors. One implication will be the impact on the product labels of imported foods. Generally speaking, food allergen regulation of imported foods has largely been overlooked. Our survey of imported foods in Australia indicates poor compliance of food allergen labelling law. Considering $40 \%$ of foods available in Australia are derived from import sources, such poor implementation of food allergen labeling of imported foods will undoubtedly increase the health risk of sensitive individuals.

In his recent review, Gendel $(2012)^{46)}$ emphasises an urgent need for risk ranking framework of major food allergens to develop an international consensus on a single list of allergens that will be appropriate for all jurisdictions for the purpose of harmonized food allergen labelling. Gendel's review also criticizes a lack of transparency on the assessment of major allergens and basis for developing current allergen lists at national levels. If reassessment of the allergen lists is called for the purpose of harmonization of food allergen regulation, true prevalence data from each involving countries will be an important resource.

Finally, it has been twelve years since the first food allergen regulation has been introduced. It is indeed time to revisit the question of whether or not this regulation has been an effective tool in serving its original intention - that is, of providing "true" food allergen status in food products, and a basis for protecting high risk individuals. What are the emerging social, economic and trade issues arising from the allergen labelling regulations? Perhaps the more urgent issue is a need to assess the current status of undeclared allergens in food products and potential exposure risks posed on the general public and food allergic individuals.

\section{Conclusion}

Food allergy is an adverse reaction to certain foods involving the immune response. Such adverse reactions of foods cause diverse symptoms from mild to even lifethreatening conditions. The estimated prevalence of food allergens based on clinical evidence is three to four-folds higher in children than in adults and affects $4-8 \%$ of children and $1-2 \%$ in adults. Prevalence of different food allergies differs drastically amongst different countries for various reasons, including life-style, dietary habits, consumption patterns, exposure age, and availability of unique foods. Milk and egg allergies are most common food allergies in children, whereas fish and shellfish allergies are more common in adults. As cure for food allergy is not currently available and total avoidance of offending foods is the recommended remedy, food allergy is thus regulated by mandatory labeling of major food allergens in pre-packaged foods since 2002. The divergences in food allergen labelling regulations among the regulated countries, however, complicate implementation and created a huge economic burden on the agricultural and food industries. It is worthy to note that food allergy is a world-wide phenomenon and, unlike other food safety regulations, the simple adoption of CODEX recommendation without properly assessing its adequacy for the intended country will not derive benefits for public safety. There is therefore an urgent need for developing country-specific prevalence data. To facilitate more effective food allergen control worldwide and to prevent food allergen labelling requirements from becoming a trade barrier, harmonization of food allergen regulations based on a priority allergen list common to all is urged.

\section{References}

1. David, T.J. : Adverse reactions and intolerance to foods. Brit. Med. Bull., 56, 34-50 (2009).

2. Cianferoni, A. and Spergel, J.M. : Food allergy: review, classification and diagnosis. Allergol. Int., 58, 457-466 (2009).

3. O'Connell, E.J. : Pediatric allergy: a brief review of risk factors associated with developing allergic disease in childhood. Ann. Allerg. Asthma Im., 90, 53-58 (2003).

4. Nurmatov, U., Devereux, G., and Sheikh, A. : Nutrients and foods for the primary prevention of asthma and allergy: Systematic review and meta-analysis. J. Allergy Clin. Immun., 127, 724-733 (2011).

5. Sellge, G. and Bischoff, S.C. : The immunological basis of IgE-mediated reactions. In: Food allergy: adverse reactions to foods and food additives, 4rd Ed. (Metcalfe, D.D., Sampson, H.A. and Simon, R.A. eds.) Blackwell Publishing Ltd., Oxford, UK. pp. 15-28 (2008).

6. Breiteneder, H. and Mills, E.N.C. : Plant food allergens - 
structural and functional aspects of allergenicity. Biotechnol. Adv., 23, 395-399 (2005a).

7. Breiteneder, H. and Mills, E.N.C. : Molecular properties of food allergens, J. Allergy Clin. Immun., 115, 14-23 (2005b).

8. Heine, R.G., Laske, N. and Hill, D.J. : The diagnosis and management of egg allergy. Curr. Allerg. Asthm. Rep., 6, 145-152 (2006).

9. Woods, R.K., Stoney, R.M. and Raven, J. : Reported adverse food reactions overestimate true food allergy in the community. Eur. J. Clin. Nutr., 56, 31-36 (2002).

10. De Boissieu, D. and Dupont, C. : Natural course of sensitization to hen's egg in children not previously exposed to egg ingestion. Eur. Ann. Allergy Clin. Immun., 38, 113-117 (2006).

11. Aabin, B., Poulsen, L.K., Ebbehøj, K., Nørgaard, A., Frøkiaer, H., Bindslev-Jensen, C. and Barkholt, V. : Identification of IgE-binding egg white proteins: comparison of results obtained by different methods. Int. Arch. Allergy Imm., 109, 50-57 (1996)

12. Host, A. : Frequency of cow's milk allergy in childhood. Ann. Allerg. Asthma Im., 89, 33-37 (2002).

13. Allen, C.W., Campbell, D.E. and Kemp, A.S. : Egg allergy: are all childhood food allergies the same?. J. Paediatr. Child H., 43, 214-218 (2007).

14. Emmett, S.E., Angus, F.J., Fry, J.S. and Lee, P.N. : Perceived prevalence of peanut allergy in Great Britain and its association with other atopic conditions and with peanut allergy in other household members. Allergy, 54, 380-385 (1999).

15. Sicherer, S.H., Muñoz-Furlong, A., Burks, A.W. and Sampson, H.A.: Prevalence of peanut and tree nut allergy in the United States determined by means of a random digit dial telephone survey: A 5-year follow-up study. J. Allergy Clin. Immun., 112, 1203-1207 (2003).

16. Grundy, J., Matthews, S., Bateman, B., Dean, T., and Arhad. S.H. : Rising prevalence of allergy to peanut in children: Data from 2 sequential cohorts. J. Allergy Clin. Immun., 110, 784789 (2002)

17. Skolnick, H.S., Conover-Walker, M.K., Koerner, C.B., Sampson, H.A., Burks, W. and Wood, R.A. : The natural history of peanut allergy. J. Allergy Clin. Immun., 107, 367-374 (2001).

18. Bock, S.A., Muñoz-Fur, L.A. and Sampson, H.A. : Fatalities due to anaphylactic reactions to foods. J. Allergy Clin. Immun., 107, 191-193 (2001).

19. van Boxtel. E.L., van Beers, M.M., Koppelman, S.J., van den Broek, L.A. and Gruppen, H. : Allergen Ara h 1 occurs in peanuts as a large oligomer rather than as a trimer. J. Agr. Food Chem., 54, 7180-7186 (2006).

20. van Boxtel, E.L., van den Broek, L.A., Koppelman, S.J. and Gruppen, H. : Legumin allergens from peanuts and soybeans: Effects of denaturation and aggregation on allergenicity. Mol. Nutr. Food Res., 52, 674-682 (2008).

21. Koppelman, S.J., Knol, E.F., Vlooswijk, R.A., Wensing, M., Knulst, A.C., Hefle, S.L., Gruppen, H. and Piersma, S. : Peanut allergen Ara h 3: Isolation from peanuts and biochemical characterization. Allergy, 58, 1144-1151 (2003).

22. Koppelman, S.J., Wensing, M., Ertmann, M., Knulst, A.C. and Knol, E.F. : Relevance of Ara h1, Ara h2 and Ara h3 in peanut-allergic patients, as determined by immunoglobulin $\mathrm{E}$ Western blotting, basophil-histamine release and intracutaneous testing: Ara 2 is the most important peanut allergen. Clin. Exp. Allergy, 34, 583-590 (2004).

23. Krause, S., Reese, G., Randow, S., Zennaro, D., Quaratino, D., Palazzo, P., Ciardiello, M.A., Petersen, A., Becker, W.M. and Mari, A. : Lipid transfer protein (Ara h 9) as a new peanut allergen relevant for a Mediterranean allergic population. $J$. allergy clin. Immun., 124, 771-778 (2009).

24. Lee, B.J. and Park, H.S. : Common Whelk (Buccinum undatum) Allergy: Identification of IgE-binding Components and Effects of Heating and Digestive Enzymes. J. Korean Med. Sci., 19, 793-799 (2004).

25. James, J.M., Helm, R.M., Burks, A.W. and Lehrer, S.B. : Comparison of pediatric and adult IgE antibody binding to fish proteins. Ann. Allerg. Asthma Imm., 79, 131-137 (1997).

26. Van Do, T., Elsayed, S., Florvaag, E., Hordvik, I. and Endresen, C. : Allergy to fish parvalbumins: studies on the cross-reactivity of allergens from 9 commonly consumed fish. J. Allergy Clin. Immun., 116, 1314-1320 (2005).

27. Bernhisel-Broadbent, J., Scanlon, S.M. and Sampson, H.A. : Fish hypersensitivity. I. In vitro and oral challenge results in fish-allergic patients. J. Allergy Clin. Immun., 89, 730-737 (1992).

28. Hansen, T.K., Bindslev-Jensen, C., Skov, P.S. and Poulsen, L.K. : Codfish allergy in adults: IgE cross-reactivity among fish species. Ann. Allerg. Asthma Im., 78, 187-194 (1997).

29. Hilger, C., Grigioni, F., Thill, L., Mertens, L. and Hentges, F. : Severe IgE-mediated anaphylaxis following consumption of fried frog legs. Allergy, 57, 1053-1058 (2002).

30. Lee, B.W., Shek, L.P-C., Gerez, I.F.A., Soh, S.E. and Van Bever, H.P. : Food Allergy-Lessons from Asia. World Allergy Organiz. J., 1, 129-133 (2008).

31. Sampson, H.A. : Update on food allergy. J. Allergy Clin. Immun., 113, 805-819 (2005).

32. Codex Alimentarius : General standard for the labeling of prepackaged foods. Codex Stan. 1-1985. (2010) Available from: http://www.codexalimentarius.org/download/standards/32/CXS _001e.pdf. Accessed Oct. 15. 2012.

33. Hadley, C. : Food allergies on the rise? EMBO Report, 7, 1080-1083 (2006).

34. van der Poel, L., Chen, J. and Penagos, M. : Food allergy epidemic - Is it only a Western phenomenon?. Curr. Allergy Clin. Immun., 22, 121-126 (2009).

35. Imamura, T., Kanagawa, Y. and Ebisawa, M. : A survey of patients with self-reported severe food allergies in Japan. Pediatr. Allergy Immun, 19, 270-274 (2008).

36. Wang, Z. : An allergy prevalence survey in population of 10,144 people. Chinese J. Epidemiol., 11, 100-102 (1990).

37. Wieslander, G., Norback, D. and Wang, Z. : Buckwheat allergy and reports on asthma and atopic disorders in Taiyuan City, Northern China. Asian Pacific J. Allergy Immun., 18, 147-152 (2000)

38. O’Neil, C.E., Zanovec, M. and Nicklas, T.A. : A review of 
food allergy and nutritional considerations in the food-allergic adult. Am. J. Lifestyle Med., 5, 49-62 (2011).

39. Codex Alimentarius : Food Labeling 5th Ed. (2005) Available from: ftp://ftp.fao.org/docrep/fao/010/a1390e/a1390e00.pdf. Accessed Oct. 15. 2012.

40. Food standards Australia New Zealand : Review of the regulatory management of food allergens (2010) Available from: http://www.foodstandards.gov.au/_srcfiles/Review\%20of\%20 the $\% 20$ Regulatory $\% 20$ Management $\% 20$ of $\% 20$ Food $\% 20$ Aller gensFSANZ\%20Dec\%202010.pdf. Accessed Oct. 2. 2012.

41. Food and Drug Administration : Food Allergen Labeling and Consumer Protection Act of 2004 (2004) Available from: http:/ /www.fda.gov/food/labelingnutrition/FoodAllergensLabeling/ Guidance Comp lianceRegulatoryInformation/ucm106187.htm. Accessed Oct. 8. 2012.

42. Health Canada : Amendments to the Food Allergen Labelling
Regulations, Canada Gazette, Part II (CGII) (2011). Available form: http://www.hc-sc.gc.ca/fn-an/label-etiquet/allergen/indexeng.php. Accessed Oct 8. 2012.

43. European Parliament : Directive 2003/89/EC of the European Parliament and of the Council of 10 November 2003 amending Directive 2000/13/EC as regards indication of the ingredients present in foodstuffs (2003) Available form: http://ec.europa. eu/food/food/labellingnutrition/foodlabelling/fl_com2003-89_ en.pdf. Accessed Oct 2. 2012.

44. Akiyama, H., Imai, T. and Ebisawa, M. : Japan Food Allergen Labeling Regulation - History and Evaluation. Adv. Food Nutr. Res., 62, 139-171 (2011).

45. Korean Food and Drug Administration : Information extracted from the USDA ARS GAIN Report KS1102.

46. Gendel, S.M. : Comparison of international food allergen labeling regulations. Regul. Toxicol. Pharm., 63, 279-285 (2012). 